\title{
Em torno do ethos discursivo e de questões de identidade
}

\author{
Jarbas Vargas Nascimento
}

\section{Introdução}

C omo contribuição aos estudos Retóricos e, particularmente, às pesquisas em Análise do Discurso de linha francesa (AD), neste capítulo, faço uma reflexão sobre a noção de ethos, cuja primeira categorização remonta à herança gregaclássica. Examino, sobretudo, como foco central deste trabalho, a noção de ethos discursivo, a complexidade dessa categoria e a dificuldade que alguns pesquisadores discursivistas revelam para operacionalizá-la como um atributo exclusivo do enunciador e não do locutor. Em seguida, reflito sobre a relação ethos dito e ethos mostrado e sobre as estratégias mobilizadas pelo enunciador para dizer-se, ou seja, apresentar-se a si mesmo ao co-enunciador e o seu modo de enunciar.

Com isso, procuro mostrar que a Retórica e a $\mathrm{AD}$ investem teoricamente, de modo diferenciado, na concepção e operacionalização do ethos. Como respaldo teórico-metodológico da abordagem de Maingueneau, o pioneiro na retomada do ethos, com base na $\mathrm{AD}$, debruço-me sobre uma prática discursiva, produzida por Bianca Santana e empreendo uma análise elucidativa, objetivando evidenciar a emergência e a constituição inevitável de um ethos, na enunciação, contribuindo, dessa forma, para o debate que se instala, sobre essa categoria e a construção da identidade, no campo da linguagem, na atualidade. 


\section{Situando o debate sobre o conceito de ethos discursivo}

Este estudo, pelo que antecede, demanda-me revisitar, com brevidade, a noção de ethos veiculada na antiguidade grega, particularmente por Aristóteles, antes de considerar a noção de ethos discursivo de um ponto de vista da $\mathrm{AD}$, no quadro em que Maingueneau inscreve essa categoria. Sem desconsiderar questões essenciais sobre a contribuição de Aristóteles a respeito dessa noção em estudo, faz-se necessário lembrar que discussão clara e detalhada sobre o ethos retórico encontra-se em Eggs $^{1}$ o que me autoriza a ser breve nesse tópico.

O supracitado autor, em sua explanação sobre o ethos retórico, adverte-nos que há, também, reflexões sobre o ethos em pesquisas de autores modernos, embora encobertos por outras problemáticas. Diante disso, Eggs explicita posicionamentos sobre ethos na Teoria dos Atos de Fala, como a questão da condição de sinceridade, em Searle ${ }^{2}$ como componente do discurso direto e indireto e no princípio da cooperação e nas máximas de Grice $^{3}$, além de máximas de polidez, de modéstia ou de generosidade em Leach ${ }^{4}$ e, até mesmo, Perelman \& Olbrechts-Tyteca ${ }^{5}$, quando tratam da pessoa e seus atos.

Por conta da relevância dessa categoria, é, na década de 1980, que Maingueneau ${ }^{6}$ trouxe à baila novas configurações sobre o ethos, ao dar ao sujeito uma posição enunciativo-discursiva, distinguindo-o do indivíduo, sujeito empírico. Diante disso, Maingueneau procura responder, com base em uma perspectiva além da lógica da argumentação aristotélica, questões relacionadas ao sujeito, por meio de uma abordagem pragmático-enunciativa sobre o discurso, sobre a $\mathrm{AD}$ e sobre o ethos, uma vez que essa categoria contribui para a legitimação do próprio discurso, que revela uma voz e um corpo enunciantes. Essa tomada de posição particulariza a $\mathrm{AD}$, embora alguns autores, entre eles Van Dijk, considerem essa disciplina um prolongamento da Retórica clássica, conforme nos lembra com a seguinte assertiva:

a análise do discurso é simultaneamente uma disciplina antiga e recente. Suas origens podem ser localizadas no estudo da linguagem,

\footnotetext{
Eggs, 2005, p. 29-56.

Searle, 1969.

Grice, 1989.

Leach, 1983.

Perelman \& Olbrechts-Tyteca, 1996.

Maingueneau, 1984.
} 
discurso público e literatura, remontando a mais de 2000 anos. Uma de suas mais importantes fontes históricas é indubitavelmente a retórica clássica, a arte de falar bem ${ }^{7}$.

Tomando como ousada essa afirmação de Van Dijk, o próprio Maingueneau adverte-nos sobre o perigo de aceitá-la como verdadeira, como se a Retórica,

ou, antes, as diferentes configurações da Retórica, não fossem solidárias de configurações do saber e de práticas irremediavelmente desaparecidas. A nosso ver, a análise do discurso implica também o reconhecimento de uma «ordem do discurso» irredutível ao dispositivo retórico. $\mathrm{O}$ que não a impede de reinvestir, não sem as reelaborar convenientemente, muitas categorias e problemáticas oriundas da Retórica ou de outras práticas ${ }^{8}$.

$\mathrm{Na}$ verdade, todo e qualquer pesquisador não deve descartar os vínculos entre as diferentes disciplinas, que operam com o discurso. Entretanto, ressalto que as interfaces que cada uma delas faz com os diversos campos do conhecimento, são positivas, ampliam esse espaço simbólico de investigação e, àqueles que pesquisam, possibilitam determinar e reconfigurar categorias como o ethos, desenvolvido primeiramente por Aristóteles, na Retórica clássica.

Ademais, na atualidade, a rapidez com que evoluem os meios de comunicação social, além da comunicação na mídia, e a necessidade de o homem se comunicar mais eficazmente, impulsiona Maingueneau a recorrer à noção de ethos, para a validação do dizer do sujeito na enunciação, reconfigurando, por conseguinte, uma estratégia discursiva de articulação garantidora da adesão do co-enunciador. Esta decisão, com efeito, parte da constatação de que a sociedade contemporânea tende a alterar constantemente suas práticas discursivas, fazendo com que o sujeito, antes passivo, se projete e invista em si mesmo, com base na ressignificação do conceito de interação, que lhe permite construir nova concepção de si e de mundo.

Desse ponto de vista, podemos dizer que acentralização no/do sujeito empírico é basilar para a Retórica, constituindo, por um lado, o ethos como uma estratégia de influência para a persuasão. Não posso negar que a Retórica aristotélica contribui, com eficácia, para a prática da persuasão, apreendendo o ethos como a imagem que orador revela de si como a prova

$7 \quad$ Van Dijk, 1985, p. 1.

8 Maingueneau, 2007, p. 16. 
mais evidente e de credibilidade de seu caráter. Por outro lado, para a AD, a imagem e a identidade enunciativas são imprescindíveis à categorização do ethos, na medida em que essa categoria se constitui na cenografia e está ligada ao discurso. Nesse sentido, o fato de o ethos ligar-se a determinadas condições de emergência e circulação do discurso leva Maingueneau' a observar a forma como, na enunciação, o sujeito investe na imagem de si e como ele fica determinado pela percepção do Outro. Por isso, a imagem que o enunciador projeta de si e o movimento que o co-enunciador mobiliza para mostrar uma imagem do enunciador são determinados pela/na interação que o discurso estabelece.

Essa retomada da noção de ethos por Maingueneau ${ }^{10}$ elucida a posiçãosujeito como uma instância subjetiva, que emerge na enunciação, constrói-se discursivamente e opera efeitos de sentido, que investem sobre a materialidade linguística. A proposta, defendida por nosso autor, considera a distinção entre o sujeito do enunciado e o sujeito da enunciação, aponta aspectos específicos da $\mathrm{AD}$ em relação ao ethos e faculta-me reiterar uma das formas como essa disciplina se afasta da Retórica aristotélica no tratamento dessa categoria. Maingueneau ${ }^{11}$ assevera, ainda, que a maior dificuldade de compreensão do ethos é não diferenciar o enunciado como um evento comunicativo empírico concretizado, espaço de interação de atores sociais e a enunciação como um ato de produção do enunciado.

Embora Benveniste, em seu artigo "O aparelho formal da enunciação $0^{12 "}$, assuma uma perspectiva estruturalista e reflita sobre os conceitos de enunciado e enunciação, vale retomá-lo, quando relaciona o emprego da língua à natureza conceitual de enunciação e de discurso. Para Benveniste, a enunciação é um processo, ou seja, um ato pelo qual o enunciador, por sua própria conta, mobiliza a língua. Nesse sentido, é o ato de apropriação da língua que introduz o sujeito no discurso. Por isso, o produto desse ato é o enunciado, e a enunciação é a tomada de posição do sujeito, que se apropria da língua, e dos recursos disponíveis nela para instaurar o Outro e colocar em funcionamento o discurso, constituindo a si próprio como referência essencial ao discurso. Desse modo, atualizando a proposta de Benveniste, posso afirmar que o ethos para a Retórica está na mobilização do sujeito locutor do enunciado enquanto para a $\mathrm{AD}$, no sujeito da enunciação.

9 Id., 2005.

10 Id., 2016.

11 Id., 2009.

12 Benveniste, 1979. 
Pelo que foi dito anteriormente, enunciado e enunciação são de duas ordens muito diferentes, pois que o enunciado impõe a fala imediata de um sujeito encarnado, enquanto a enunciação exige do co-enunciador um trabalho de elaboração imaginária, a partir de marcas textuais diversificadas. É possível distinguir que no caso específico dos estudos retóricos, o ethos do orador e o pathos do auditório coexistem no processo de persuasão e, na $\mathrm{AD}$, o ethos se manifesta na cena enunciativa.

Acredito que ainda que complexa esta distinção, o ponto de vista acima faz com que as duas disciplinas se diferenciem na concepção dessa categoria. Assim, no entender de Maingueneau

o enunciado se opõe à enunciação da mesma forma que o produto se opõe ao ato de produzir; nesta perspectiva, o enunciado e a marca verbal do acontecimento que é a enunciação. Aqui, a extensão do enunciado não tem nenhuma importância: pode-se tratar de algumas palavras ou de um livro inteiro. Essa definição de enunciado é aceita universalmente ${ }^{13}$.

Penso que posso, ainda, retomar a reflexão de Charaudeau, que distingue o sujeito social do sujeito enunciador. Essa distinção me move a diferenciar a abordagem do ethos retórico e do ethos discursivo, na medida em que, para Charaudeau ${ }^{14}$, o locutor é um sujeito social que, por um lado, assume a palavra e que funda sua legitimidade de ser comunicante em função do estatuto e do papel social que lhe são atribuídos pela situação de comunicação e, por outro, o sujeito enunciador é aquele que enuncia, uma unidade discursiva que se atém aos papéis que ele se atribui em seu ato de enunciação, resultado das coerções da situação de comunicação que se impõe a ele e das estratégias que ele escolhe seguir.

Como a concepção de ethos, nas perspectivas linguístico-discursivas ora equivalem ao sujeito social, ora ao sujeito enunciador, ou ainda, ao enunciado e à enunciação, sou levado a reafirmar que essa categoria se tornou uma estratégia muito complexa, mas muito produtiva, inclusive pela quantidade de pesquisas significativas publicadas em torno dessa noção. Diante disso, posso dizer, de partida, que a noção de ethos é assumida diferentemente e muda de acordo com o aparato teórico-metodológico de que nos cercamos para concebê-lo. O mesmo acontece com o termo discurso e enunciado e

13 Maingueneau, 2013, p. 63.

14 Charaudeau, 2006, p. 115. 
enunciação, que no interior da Linguística, desde o Estruturalismo até as recentes vertentes da Linguística contemporânea assumem concepções e tratamento diferenciados, resultando em investigações não idênticas. Estudos como o de Maingueneau ${ }^{15}$ ratificam a afirmação que enfatizo acima e mudam as condições de exercício da pesquisa.

A perspectiva da Retórica aristotélica confirma a importância do ethos, do pathos e do logos como estratégias de persuasão pela ética, pela emoção e pela lógica, respectivamente, mas é o orador que as provoca no auditório. Nesse sentido, o orador, pelo olhar do auditório, recebe uma identidade social e psicológica, no mesmo instante em que constrói para si uma identidade. Em outras palavras, posso dizer que o ethos, o pathos e o logos, na medida em que se relacionam ao orador e à situação na qual essas estratégias se manifestam, permitem ao auditório construir uma imagem daquele que fala no discurso. Na perspectiva da $\mathrm{AD}$, a questão do ethos passa por representações sociais. Charaudeau esclarece que

quando Maingueneau retoma a noção de "tom" - proposta por Barthes a partir da noção de "ares" de Aristóteles - e propõe "uma concepção mais encarnada de ethos", como atributo do que ele chama de fiador de um caráter e de uma corporalidade subjetiva, é, ainda, de representação social que se trata, uma vez que a visão que uma sociedade tem do corpo depende dos imaginários coletivos que ela constrói para si. Diremos que o ethos apoia-se em um duplo imaginário corporal e moral ou que é um imaginário que, aqui, se "corporifica"16.

Assim, parece-me ficar mais evidente a compreensãode que a noção de ethos constrói-se na enunciação, ou seja, todo discurso exige um sujeito, que assume um corpo, que se diz no interior de uma comunidade imaginária (enunciativa) daqueles que adotam o mesmo discurso no relacionamento com o mundo. É preciso acentuar que, na $\mathrm{AD}$, a imposição de um retorno crítico à categoria de ethos, conforme Maingueneau ${ }^{17}$, se fundamenta em questões contemporâneas relacionadas, in essentia, ao discurso e ao sujeito, nos campos da Linguística e da Comunicação.

Reforço ainda que o ethos se constitui na cenografia por meio de uma construção semântico-discursiva e não por marcas psicológicas ou morais

15 Maingueneau, 2007; 2015a.

16 Charaudeau, op.cit., p. 117.

17 Maingueneau, 2016. 
do locutor, até por que, na $\mathrm{AD}$, ethos, corporificado no discurso, se apresenta como uma categoria complexa. Entretanto, lembro Amossy ${ }^{18}$, quando postula que todo ato de tomar a palavra implica a construção de uma imagem de si.

\section{Novas perspectivas sobre o ethos discursivo na trajetória de Maingueneau}

Data de 1980, o início de uma atitude, configurada como pós-moderna pois que, naquele momento, se propôs um afastamento do objeto para estabelecer uma supervalorização do sujeito. Com isso, resgata-se e eleva-se a posição-sujeito e faz-se com que o ethos assuma amplo e total interesse em diferentes áreas do conhecimento. No caso específico dessa mudança de foco do objeto para o sujeito, fez surgir, na França, em 1984, as primeiras investigações sobre o ethos, com base em perspectivas pragmáticas ediscursivas. Exemplo disso, são os estudos de Ducrot, que integra o ethos em uma abordagem enunciativa e Maingueneau ${ }^{19}$, em uma abordagem enunciativo-discursiva. A respeito disso, Ducrot ${ }^{20}$ afirma que o ethos evoca o sujeito responsável pela enunciação, por isso ele se projeta como fonte enunciativa. Entretanto, Ducrot, para tratar do ethos, distingue o locutor-L, uma entidade enunciativa, e o locutor-lambda, sujeito falante, empírico e postula uma diferença entre mostrar e dizer, para esclarecer que o ethos se mostra; ele não é dito.

Embora Maingueneau tenha se debruçado sobre a noção de ethos discursivo em diferentes ocasiões de sua vasta produção, por questão de espaço neste capítulo, lembro apenas que algumas de suas reflexões são pouco definidas, mas profundamente reflexivas, como as que se encontram em Novas Tendências em Análise do Discurso, em Análise de Textos de Comunicação, em Gênese do discurso, no capítulo intitulado Ethos, cenografia incorporação, publicado no livro de Amossy, em Cenas de Enunciação, Gênese do Discurso, no Discurso Literário ${ }^{21}$. Parece-me necessário informar, também, que essas constantes reformulações do conceito de ethos discursivo propostas por Maingueneau se justificam, na medida que qualquer novo entendimento

\footnotetext{
18 Amossy, 2005, p. 9.

19 Maingueneau, 1997; 2005.

20 Ducrot, 1987, p. 201.

21 Maingueneau, 1997, 2001, 2005, 2008a, 2008b, 2018.
} 
se defrontacom questões epistemológicas e outras decorrentes do desenvolvimento sociocultural e dos limites semânticos, pragmáticos, históricos e discursivos dessa categoria. É o próprio Maingueneau ${ }^{22}$ quem diz que o ethos permanece uma categoria insuficientemente especificada para ser a medida da diversidade das situações de comunicação. Muitos desdobramentos poderão vir, resultantes de novos posicionamentos.

Em estudo mais recente, Maingueneau ${ }^{23}$ retoma as reflexões feitas anteriormente e reafirma que o ethos fundamenta-se em uma perspectiva sociodiscursiva, constitui-se na enunciação e estabelece uma interação com o co-enunciador. Como se trata de uma atitude socialmente avaliada, sua manifestação somente pode ser compreendida na enunciação, isto é, em uma cenografia e em determinada condição sócio-histórico-cultural. $\mathrm{Na}$ verdade, o ethos discursivo é, pelo que antecede, uma manifestação subjetiva, emerge na enunciação e engloba o ethos dito, sinalizado por referências diretas, e o ethos mostrado, construído por pistas que o enunciador oferece, no funcionamento do discurso; mas que ele pode não estar explicitamente ali representado. Por esse tipo de comportamento do enunciador, abre-se ao co-enunciador a possibilidade de imaginar e atribuir traços físicos e de caráter, que ocorporificam, com base emrepresentações sociais valorizadas ou não por estereótipos culturais, que são reforçados ou transformados ${ }^{24}$.

O posicionamento, aqui levantado, fica mais claro quando Maingueneau explica que

o 'caráter' corresponde a um conjunto de características psicológicas. A 'corporalidade', por sua vez, associa-se a uma compleição física e a uma maneira de se vestir. Além disso, o ethos implica uma maneira de se movimentar no espaço social, uma disciplina tácita do corpo apreendida mediante um comportamento global. O destinatário o identifica com base num conjunto difuso de representações sociais avaliadas de modo negativo ou positivo, de estereótipos que a enunciação contribui para confirmar ou modificar $^{25}$.

Não obstante estudos anteriores, Maingueneau retoma, mais uma vez, de maneira mais crítica, o conceito de ethos discursivo. A pesquisa mais atual de

\footnotetext{
Id., 2016, p. 24.

Id., 2016.

Id., 2016.

Id., 2018, p. 271-272.
} 
Maingueneau retoma criticamente seus posicionamentos anteriores e revisita a noção de ethos, distinguindo três dimensões: a categorial, a experiencial e a ideológica em função de diferentes gêneros de discurso. Para ilustrar esse novo momento de pesquisa em torno da categoria ethos discursivo, Maingueneau recorre a corpora de anúncios de sites de relacionamento e finaliza trabalhando com textos em que as dimensões verbal e icônica estão estreitamente ligadas, para considerar os sites da Internet, nos quais estão implicados ethos verbal e ethos digital, e as publicidades.

Ainda que a noção de ethos discursivo seja, de certo modo, intuitiva, e resultante da interação entre o ethos dito e o ethos mostrado o esquema abaixo, formulado em condições bem didáticas com base em Maingueneau, é bastante claro, quando se quer propor uma categorização, que visa à reconstrução da identidade, resultante da interação entre o enunciador e o co-enunciador. $\mathrm{O}$ ethos, nesse sentido, organiza o discurso, na medida em que integra um componente identitário, que se explicita, por meio de estereótipos ligados ao mundo ético, de acordo com os efeitos de sentido objetivados pelo enunciador.

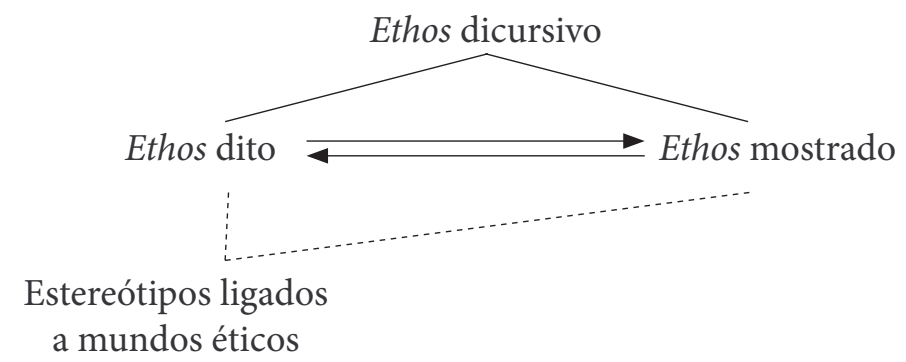

Fonte: Adaptação de Maingueneau (2018, p. 270). 
No meu entendimento, a constituição de uma imagem do sujeito no discurso se situa, como mostro na análise que se seguirá, entre o posicionamento do enunciador que se diz para propor uma condição a seu favor e uma dimensão ideológica, que exprime normas étnico-sociais, configuradas por eventos vivenciados. O discurso, nessa perspectiva, está ligado à prática e, em função disso, torna-se lugar de constituição de sujeitos com suas manifestações de vivências reflexivas e afetivas

Compreendida a noção de ethos discursivo, passo agora a operacionalizá-la e, para tal, selecionei um fragmento de um discurso produzido por Bianca Santana, jornalista e escritora negra brasileira, vencedora do Prêmio Jabuti, em 2016, na categoria ilustração. O discurso selecionado encontra-se na obra "Quando me descobri negra", publicada em 2015, em que a autora relata a sua experiência de vida e relaciona-a a de outros negros, mostrando a dificuldade de autotransparência e a impossibilidade de rompimento das imposições sócio-histórico-culturais que incidem sobre sua condição de mulher negra. Desse modo, cada evento vivido impede-a de um olhar positivo sobre si mesma e sobre outros negros, até libertar-se, ressignificando-se. No relato que escolhi, apreendido aqui como discurso, Bianca Santana constitui um enunciador que cria uma cenografia na qual encena uma percepção do que passou ao longo da vida e que resultou na conscientização da cor de sua pele, estigma determinante de sua existência e de seus posicionamentos e fundamentais para a compreensão ética do ser humano.

De partida, posso afirmar que o título "Tenho 30 anos, mas sou negra há dez. Antes, era morena” propõe uma condição sócio-histórica problemática a ser explicitada, denunciada e avaliada concomitantemente, pois causa ao co-enunciador um efeito de sentido, que o leva a interessar-se e a aderir ao dito do enunciador. É um indício de que se constitui aqui um ethos dito, que afiança uma pessoalidade, uma imagem de si mesmo como enunciador, marcada pelo código linguageiro constitutivo dessa enunciação. Desse ponto de vista, o título funciona como uma estratégia que cumpre um contrato, determina uma condição em um tempo real, que pode ser compartilhado pelo co-enunciador, de forma a testemunhar uma questão problemática da sociedade brasileira, possível de enfrentamento, pois a discriminação étnico-racial se identifica como um comportamento social maligno. Além disso, levando em conta sua inserção sócio-histórico-cultural, esse título resume e incita o co-enunciador a compreender o alcance dessa questão, no funcionamento discursivo, em que o instaura e confere-lhe autoridade. A cenografia prevista pela enunciação do título desse discurso aponta para 
um conjunto de topografias discursivas tensas, que constituirão espaços de enunciação testemunhal da vida do enunciador.

\section{Recorte 1}

Se descobrir negro é desesperador e libertador ao mesmo tempo. Sempre soube que era mulher pelas limitações que me impuseram em casa, das coisas que meu irmão podia fazer e eu não podia por ser menina. Na escola descobri que eu era gorda, presente dos comentários e apelidos colocados pelas outras crianças. Mas crescendo na periferia, eu achava que racismo não existia. Claro que tinham pessoas negras e brancas, mas meus amigos brancos eram enquadrados pela polícia assim como meus amigos negros. Todos nós éramos pobres, para mim era isso que nos tornava iguais.

Nesse recorte, abordo, em primeiro lugar, as condições sócio-históricas e culturais de produção que dão origem a esse discurso testemunhal e autobiográfico. Ainda que se reduza o espaço e o tempo à atualidade, historicamente, a sociedade brasileira patenteia, também, um racismo estrutural, pois que quer tornar o país embranquecido, apagando os vestígios culturais da africanidade. A escravatura do negro, no Brasil, trouxe marcas que coexistem na sociedade brasileira contemporânea, por meio de situações de tensão sobre o indivíduo e a coletividade, proibindo ao negro condições dignas de vida e de convívio social.

Embora o enunciador não se dirija a um co-enunciador explícito, o discurso é essencialmente interativo e a forma como organiza esse discurso faz com que se depreenda uma cenografia de diálogo consigo mesmo. Tal fato força o enunciador a mostrar um comportamento próprio de uma sociedade preconceituosa, baseada na cor da pele, na discriminação de gênero, na gordofobia e na exclusão pela classe social. Como é a cenografia que revela as verdadeiras redes semânticas do discurso, nela o co-enunciador depreende os deslizamentos semânticos, as limitações, as rupturas e as transformações, que mostram a imagem daquele que enuncia. $\mathrm{O}$ ethos mostrado, nesse recorte, é de um sujeito marcado por sentimentos dolorosos, excluído e esmagado por preconceitos diversos, como se vê nos enunciados:

Se descobrir negro é desesperador e libertador.

Sempre soube que era mulher .... meu irmão podia fazer e eu não podia por ser menina. 
Na escola, descobri que eu era gorda, Mas crescendo, na periferia, eu achava que racismo não existia.

Claro que tinham pessoas negras e brancas, mas meus amigos brancos eram enquadrados pela polícia assim como meus amigos negros.

Todos nós éramos pobres, para mim era isso que nos tornava iguais.

Como podemos observar nos enunciados acima, os sujeitos relatados trazem à tona outros co-enunciadores com marcas de inferioridade social, todos ancorados em uma condição sócio-histórica em que o corpo perturba e causa um silenciamento. $\mathrm{O}$ código linguageiro e os posicionamentos impõem, pela memória discursiva do enunciador, um efeito de sentido de interpelação. De fato, o ethos mostrado corresponde a valores ideológicos e sociais que o enunciador assume para denunciar e defender seu direito à vida digna.

Ainda, os itens lexicais negro, mulher, gorda, periferia, polícia, pobres são responsáveis pela sustentação do discurso, acionam cargas semânticas, que diagnosticam preconceitos sociais e permitem repensar a condição da negritude e do ser humano frente às instituições sociais, particularmente a escola, como espaço de descoberta. O ethos dito estabiliza e dá coerência ao ethos mostrado, ao mesmo tempo em que autoriza a emergência de um corpo, o do enunciador e o da comunidade imaginária daqueles que aderem a esse discurso. Assim, compreendemos melhor a eficácia de um discurso de denúncia, quando objetiva a adesão do co-enunciador.

\section{Recorte 2}

Precisei sair da periferia para perceber que não éramos. $\mathrm{Na}$ minha certidão de nascimento eu sou branca. Meu pai é um homem negro, minha mãe não. Eu sempre tive a pele mais clara que meus irmãos, embora meu cabelo fosse mais crespo. Passei a vida ouvindo que meu cabelo era ruim, sendo chamado de juba, Bombril, vassoura e outros apelidos por causa dos fios que se recusavam a crescer escorridos como o cabelo da minha mãe crescia. Meu primeiro alisamento foi com oito anos de idade. Depois disso foi uma sequência de produtos mal cheirosos que me causavam dor, mas sentir os fios balançando compensavam. Para mim, meu cabelo crespo era só um cabelo crespo e não um sinal da minha negritude. 
Nesse segundo recorte, o enunciador prossegue construindo uma cenografia de relato de si, como no recorte anterior, mas de modo mais realista, pois apresenta uma ocorrência norteadora; sair da periferia, como o lugar do negro e da pobreza, sem decisão própria, evidencia uma enunciação histórica, um ethos mostrado que faz o co-enunciador aderir. Nesse sentido, o ethos revela aspectos da identidade do enunciador, que inclui sua origem parda, cabelo crespo/ruim e os apelidos. De modo geral, os apelidos, como uma criatividade linguística, implicam uma dimensão social e outra intersubjetiva da linguagem, visto que juba, Bombril, vassoura impulsionam a construção de uma identidade particular, ou seja, uma relação direta do ethos mostrado e as referências impostas pelo código linguageiro no que se refere à denúncia instaurada no discurso. Por meio de recursos linguísticos com carga semântica negativa, esses apelidos criam uma realidade comunicativa que leva o co-enunciador a depreender um ethos dito, caracterizando a identidade do enunciador.

\section{Recorte 3}

Só percebi que eu era negra na vida adulta, graças a um segurança do mercado que me seguiu pelos corredores, graças à senhora que achou que eu trabalhava no estabelecimento, mesmo eu não usando nenhum crachá ou uniforme que me identificasse como funcionária, graças à vendedora que me ignorou, mas atendeu prontamente à cliente loira que entrou na loja depois de mim.

Fundamentado por esse recorte, posso dizer que o discurso em análise, não apresenta somente uma reflexão subjetiva do enunciador, que nele se diz, mas avança, na medida em que sua identidade, seu ethos é mostrado pelo olhar do outro, o co-enunciador, em um processo de interação social, constitutivo do discurso, na perspectiva que abordamos. A cenografia engendrada, reforça as consequências da herança histórico-social do negro e permite que o co-enunciador, em meio a uma negociação de efeitos de sentido, marcado por mecanismos discursivo-ideológicos relacionados à história do Brasil, atribua um ethos ao enunciador. Na verdade, o ethos que se constrói para o enunciador, apoia-se no ethos mostrado.

\section{Recorte 4}

Até eu ter meu próprio dinheiro eu não era negra, era morena. É triste que precisemos de um tapa na cara pra notar quem somos, 
mas é libertador ainda assim. Sei que sou uma mulher negra, sei que o meu cabelo faz parte de quem eu sou, sei que não importa se vou usá-lo crespo ou alisado, eu continuo sendo uma mulher negra e agora sei o quanto isso é libertador.

Uma identidade discursiva de libertação é constituída pelo enunciador nesse recorte e faz com que ele explicite, por um imaginário sociocultural, um ethos de um sujeito que reatualiza a vivênciadas ações narradas e que, por isso, dá-se o direito de descrevê-las, mencioná-las, constituindo uma cenografia que, de seu ponto de vista, sustenta a verdade enunciada. Essa atitude do enunciador cria um efeito de adesão por meio do relato de situações sequenciadas em que o outro ativa sua consciência identitária. Constatamos aqui a forma como o discurso se marca por definir identidades: precisamos de um tapa na cara para notar quem somos.

Desse modo, a cenografia apresenta, em primeiro plano, um sujeito descrito por uma série de marcas estigmatizadas: Sei que sou uma mulher negra, sei que o meu cabelo faz parte de quem eu sou, sei que não importa se vou usá-lo crespo ou alisado, eu continuo sendo uma mulher negra e agora sei o quanto isso é libertador. Afinal, ser libertador é reconhecer sua própria identidade, dito por meio do ethos discursivo. Aliás, a esse respeito, parece-me necessário reafirmar que, na $\mathrm{AD}$, o sujeito investe na imagem de si e ele se torna determinado pela percepção do co-enunciador.

\section{Recorte 5}

Demorei pra entender que eu era negra, e demorei mais ainda pra aceitar que eu era negra. Nos livros que eu lia não haviam negros. Nos filmes que eu assistia eles estavam presentes como escravos, criados, bandidos, e eu não queria ser nada daquilo. Imagino se na minha juventude, nas mídias que eu consumia existissem super -heroínas, princesas, mulheres negras em cargo de chefia, que não estivessem lá para servir, mas para contar uma história, talvez esse reconhecimento não fosse tão tardio, ou a aceitação tão dramática.

Nesse recorte, o enunciador constrói uma cenografia em que, por meio de uma reflexão particular, se identifica como negro, recupera o entendimento de sua situação e apresenta, no funcionamento discursivo, a aceitação de 
sua condição, conforme observamos em: Demorei pra entender que eu era negra, e demorei mais ainda pra aceitar que eu era negra.

Entretanto, é por meios de recursos outros que o enunciador, pelo apagamento, busca constituir sua identidade, na relação como observamos em: nos livros não haviam negros; nos filmes, os negros ocupavam ofícios inferiores; na mídia, os negros estavam ali para servir. Assim, na constituição do ethos discursivo, o enunciador interage com diferentes eventos, tais como aqueles internos ao discurso, como a opção pelo código linguageiro, passando por outros de diferentes ordens: livros, filmes, mídia etc. Para Maingueneau ${ }^{26}$, o ethos se elabora por meio de uma percepção complexa que mobiliza a afetividade do intérprete, que tira suas informações do material linguístico, que organiza o discurso e do ambiente.

\section{À guisa de considerações finais}

A problemática aqui discutida é a do ethos discursivo, porém percebo que o processo analítico dessa categoria não está totalmente solucionado até mesmo pelo próprio Maingueneau que assume a dificuldade de análise do ethos em determinados discursos, como, por exemplo, no filosófico

No percurso que fizemos ao longo desse capítulo e na análise busquei, com apoio da $\mathrm{AD}$, mais especificamente de Maingueneau, entender o ethos como caracterizador de uma subjetividade da linguagem que, por sua vez, está ligado ao discurso, constitui-se na cenografia e estabelece relações diretas com os estereótipos sociais, por ser uma imagem instituída por posicionamentos, crenças e valores. Essa construção enunciativa reflete um indivíduo socialmente corporificado, materializado nas estruturas sociais, mas que se torna parte do discurso, no instante em que a situação comunicativo-enunciativa é estabelecida

Refletir sobre o ethos discursivo é, portanto, pensar sobre a manifestação do sujeito no processo discursivo. Além disso, é pensar um sujeito que deixa suas marcas no discurso, porquanto é referência constitutiva no processo de interação e opera com recursos e mecanismos linguístico-discursivos, que lhe dão identidade social e discursiva necessárias ao diálogo com outros sujeitos. Por essa dinâmica discursivao enunciador cria, recria e reatualiza a

26 Maingueneau, 2008, p. 60-61. 
linguagem, que materializa posicionamentos sócio-histórico-culturais, como mostrei na análise. Na própria concepção de ethos discursivo, mostrei como a identidade humana está refletida na/pela linguagem e como ela constrói e desconstrói posicionamentos, ao instaurar o discurso. 


\section{Referências}

AMOSSY, R. (org.). Imagens de si no discurso - a construção do ethos. São Paulo: Contexto, 2005.

AUSTIN, J. L. Quando dizer é fazer. Porto Alegre: Artes Médicas, 1990.

BENVENISTE, E. (1970). O aparelho formal da enunciação. In: BENVENISTE, E. Problemas de linguística geral II. Tradução Eduardo Guimarães et al. Campinas, Pontes, 1989. p. 81-90.

BARONAS, R. L. Ensaios em Análise do Discurso - questões analíticosteóricas. São Carlos: Edufscar, 2011.

CARLOS, A. M. \& ESTEVES, A. R. Narrativas do eu: memórias através da escrita. Assis: UNESP, 2009.

CHARAUDEAU, P. Discurso político. São Paulo: Contexto, 2006. , "Identidade social e identidade discursiva, o fundamento da competência comunicacional", In: PIETROLUONGO, M. (Org.) O trabalho da tradução. Rio de Janeiro: Contra Capa, 2009, p. 309-326. 2009. Acesso em 5 out de 2019: http://www.patrick-charaudeau.com/Identidade-social-e-identidade.html.

DUCROT, O. O dizer e o dito. São Paulo: Pontes, 1987.

EGGS, E. Ethos retórico, convicção e pragmática moderna. In: AMOSSY, R. (org.). Imagens de si no discurso: a construção do ethos. Tradução de Dilson Ferreira da Cruz, Fabiana Komesu e Sírio Possenti. 2. ed. São Paulo: Contexto, 2016b. p. 29-56.

GRICE, P. Studies in the Way of Words. Boston, Harvard University Press, 1989.

LEACH, E. Aspectos antropológicos da linguagem: categorias animais e insulto verbal. In: LEACH, E. Antropologia. São Paulo: Ática, 1983. p. 170-198.

MAINGUENEAU, D. Novas tendências em Análise do Discurso. São Paulo: Pontes, 1997.

UFMG, 2000. . Termos-chaves da Análise do Discurso. Belo Horizonte:

Cortez, 2001.

. Análise de textos de comunicação. 6. ed. ampl. São Paulo:

. Diversidade dos gêneros de discurso. In: MACHADO, I. L.; MELLO, R. de. (Org.). Gêneros: reflexões em análise do discurso. Belo Horizonte: NAD/FALE/UFMG, 2004.

. Ethos, cenografia, incorporação. In: AMOSSY, R. (org.). Imagens de si no discurso: a construção do ethos. Tradução de Dílson Ferreira da Cruz, Fabiana Komesu e Sírio Possenti. 2. ed. São Paulo: Contexto, 2005. pp. 69-92. 
n. 20, p. 13-37, 2007.

. A Análise do Discurso e suas fronteiras. Matraga, [S.1.], v. 14, . Cenas da enunciação. São Paulo: Parábola, 2008a. . Gênese do discurso. São Paulo: Parábola, 2008 b.

. Doze conceitos em análise do discurso. São Paulo: Parábola, 2010. . Discurso e análise do discurso. São Paulo: Parábola, 2015a.

. O que pesquisam os analistas do discurso. Revista da ABRALIN, v.14, n.2, p. 31-40, jul./dez. 2015b

. Retorno crítico sobre o ethos. In: BARONA, R. L.; MESTI, P. C.; CARREON, R. de O. (org.). Análise do discurso: entorno da problemática do ethos, do político e de discursos constituintes. Campinas: Pontes, 2016.

Discurso literário. São Paulo: Contexto, 2018.

MOTTA, A. R.; SALGADO, L. Ethos discursivo. São Paulo: Contexto, 2008.

NASCIMENTO, J. V.; FERREIRA, A. (orgs.). Discurso e Cultura. Vol I. São Paulo: Blucher, 2018.

PERELMAN, C.; OLBRECHTS-TYTECA, L. Tratado da Argumentação - A Nova Retórica. São Paulo: Martins Fontes, 1996

SANTANA, B. Quando me descobri negra. São Paulo: SESI, 2015.

SEARLE, J. Speech Acts. Cambridge: Cambridge University Press, 1969.

SOUSA, M. W. Sujeito, o lado oculto do receptor. (org.). São Paulo: Brasiliense, 2002.

SOUZA, OLÍMPIA M., SILVA, V., ALMEIDA, E.; BISINOTO, L. S. J. (orgs.). Discurso, sujeito e memória. Campinas: Pontes, 2012.

SULLET- NYLLANDER, F. Titres de presse et polyphonie. Romansk Forum, no. 16 2002/2, XV, Skandinaviske, romantiatcongress, Oslo, 2002, pp 767-775.

VAN DIJK, T. Discourse analysis as a new cross-discipline. In: VAN DIJK, T. (ed.) Handbook of Discourse Analysis, vol.1. New York: Academic Press, p. 1- 10, 1985.

VOLOCHINOV, V. N. A construção da enunciação e outros ensaios. Trad. João Wanderley Geraldi, São Carlos: Pedro \& João, 2013. 